\title{
Loeys-Dietz: Anything special for tomorrow's case?
}

\author{
Marc Hassid, MD
}

\author{
From the Department of Anesthesia and Perioperative Medicine, Medical University of South Carolina, \\ Charleston, SC \\ Disclosures: Author has nothing to disclose with regard to commercial support. \\ Received for publication Oct 17, 2018; accepted for publication Oct 18, 2018; available ahead of print Nov 17, \\ 2018. \\ Address for reprints: Marc Hassid, MD, Anesthesia and Perioperative Medicine, Medical University of South Car- \\ olina, 167 Ashley Ave, Suite 301, MSC 912, Charleston, SC 29425 (E-mail: hassid@musc.edu). \\ J Thorac Cardiovasc Surg 2019; 157:e57 \\ $0022-5223 / \$ 36.00$ \\ Copyright (C) 2018 by The American Association for Thoracic Surgery \\ https://doi.org/10.1016/j.jtcvs.2018.10.092
}

In this issue of the Journal, Zhang and colleagues ${ }^{1}$ describe their experience anesthetizing 2 children with Loeys-Dietz Syndrome (LDS) for aortic aneurysm repair with circulatory arrest. This is the first report of anesthesia for pediatric patients with LDS undergoing aortic aneurysm surgery. Although this report lacks many of the fine details of the anesthetic that would allow close replication of their efforts, Zhang and colleagues ${ }^{1}$ do highlight several challenging aspects of anesthetizing pediatric patients with LDS. Hemodynamic control is paramount to avoid rupture of these delicate aneurysms. Zhang and colleagues ${ }^{1}$ achieved this with a seemingly routine opioid-based anesthetic and were prepared to administer 2 supplemental antihypertensive agents. In addition, this report highlights the utility of bronchial blockers for achieving single-lung ventilation in patients of insufficient size to use double-lumen endotracheal tubes. Finally, gentle airway management was justified by the concerns for joint laxity. The craniofacial manifestations of LDS, although worth mentioning, did not prohibit routine intubation.

LDS is a rare genetic connective tissue disorder first described in 2005 in which patients have characteristic craniofacial findings and may present with aneurysm formation throughout the arterial system at relatively young ages. ${ }^{2}$ The observation that these aneurysms have a propensity to rupture even when small translates into the need for careful surveillance and often surgical intervention early in life. $^{3}$

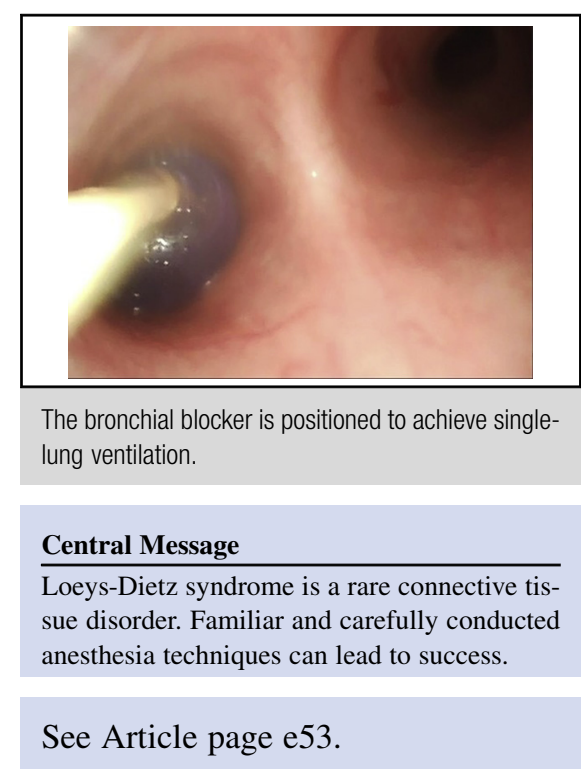

Anesthesiologists may initially be justifiably dyspeptic when tasked with anesthetizing a young child with a rare, recently described connective tissue disorder and dramatic aortic aneurysm. Johnson and colleagues ${ }^{4}$ have previously provided a detailed account of their perioperative considerations when faced with management of a young adult with LDS undergoing aortic aneurysm repair. Zhang and colleagues ${ }^{1}$ add to this with their experience caring for 2 pediatric patients. What we can surmise from these reports is that careful anesthesia with familiar techniques can result in successful outcomes for these patients.

\section{References}

1. Zhang Y, Chen L, Ji H, Yan F. Anesthesia for aortic surgery with circulatory arrest in children with Loeys-Dietz syndrome. J Thorac Cardiovasc Surg. 2019;157: e53-5.

2. Loeys BL, Chen J, Neptune ER, Judge DP, Podowski M, Holm T, et al. A syndrome of altered cardiovascular, craniofacial, neurocognitive and skeletal development caused by mutations in TGFBR1 or TGFBR2. Nat Genet. 2005;37:275-81.

3. Williams JA, Loeys BL, Nwakanma LU, Dietz HC, Spevak PJ, Patel ND, et al Early surgical experience with Loeys-Dietz: a new syndrome of aggressive thoracic aortic aneurysm disease. Ann Thorac Surg. 2007;83:757-63; discussion S785-90.

4. Johnson JG, Bray JP, Risher WH, Kaye AD. Loeys-Dietz syndrome: perioperative anesthesia considerations. Middle East J Anaesthesiol. 2016;23:569-76. 